\title{
Sophie Albert (dir.), Laver, monder, blanchir. Discours et usages de la toilette dans l'Occident médiéval
}

\section{Maria Colombo Timelli}

\section{(2) OpenEdition}

1 Journals

\section{Édition électronique}

URL : https://journals.openedition.org/studifrancesi/25977

DOI : 10.4000/studifrancesi.25977

ISSN : 2427-5856

Éditeur

Rosenberg \& Sellier

\section{Édition imprimée}

Date de publication : 1 avril 2007

Pagination : 151

ISSN : 0039-2944

\section{Référence électronique}

Maria Colombo Timelli, « Sophie Albert (dir.), Laver, monder, blanchir. Discours et usages de la toilette dans l'Occident médiéval », Studi Francesi [En ligne], 151 (LI | I) | 2007, mis en ligne le 30 novembre 2015, consulté le 23 novembre 2021. URL : http://journals.openedition.org/studifrancesi/25977 ; DOI : https://doi.org/10.4000/studifrancesi.25977

Ce document a été généré automatiquement le 23 novembre 2021.

\section{(c)}

Studi Francesi è distribuita con Licenza Creative Commons Attribuzione - Non commerciale - Non opere derivate 4.0 Internazionale. 


\title{
Sophie Albert (dir.), Laver, monder, blanchir. Discours et usages de la toilette dans l'Occident médiéval
}

\author{
Maria Colombo Timelli
}

\section{RÉFÉRENCE}

SOphie ALBERT (dir.), Laver, monder, blanchir. Discours et usages de la toilette dans l'Occident médiéval, Paris, PUPS («Cultures et civilisations médiévales», 37), 2006.

Résultat d'une journée d'études du groupe Questes (Sorbonne, 14 mai 2005), ce volume contient trois contributions centrées sur la littérature française médiévale.

2 À partir d'un corpus romanesque comprenant le Lancelot en prose, Amadas et Ydoine, le Chevalier au Lion, Partonopeu de Blois, Gliglois, Aucassin et Nicolette, Pierre LEVRON (La clinique cosmétique, ou comment laver la mélancolie. Enquête sur les textes littéraires des XII et XIII siècles, pp. 51-68) met d'abord en relief le rapport entre l'invention littéraire et les pratiques médicales contemporaines, pour passer ensuite à l'analyse des conditions et fonctions du bain dans les textes narratifs: les protagonistes sont soumis au bain après une crise grave de mélancolie ou de folie, et cette pratique, toujours confiée à des figures apaisantes et stabilisatrices, s'avère être une thérapie capable de rétablir le héros dans sa fonction individuelle et sociale.

3 Fondée aussi sur des textes narratifs, romans, lais et fabliaux, l'étude de Mathilde GRODET (L'eau et le sang. Bains délicieux, bains périlleux dans quelques récits des XII et XIII ${ }^{e}$ siècles, pp. 85-98) concerne les valeurs symboliques et le système qui oppose l'eau et le sang dans les épisodes de bain. Bain guérisseur associé au pansement des plaies ou à la saignée, bain érotique où l'eau et le sang assument des valeurs ambiguës, bain dangereux pouvant entraîner la mort, cette pratique maintient un fort contraste entre l'eau (symbole de la femme, de la pureté, de la vie) et le sang (associé à l'homme, à la souillure, à la mort). 
4 Ayant constaté que le thème du nettoyage est bizarrement moins fréquent dans les textes que l'action opposée du noircissement du visage et de la chevelure, Damien DE CARNÉ (Toilette et reconnaissance. Typologie d'un motif littéraire (XII ${ }^{\mathrm{e}}-\mathrm{XV}$ siècle), pp. 117-134) s'interroge sur le fonctionnement de ce double motif. Il constate ainsi l'existence de situations narratives typiques: le grimage par une herbe complétant un déguisement vestimentaire, le lavage de la peau pouvant se faire par l'eau et/ou par un onguent; surtout, il doit remarquer que, si le lavage ne suscite que rarement à lui seul la reconnaissance, il constitue néanmoins un signal narratif qui manifeste la clôture d'un segment narratif et qui revêt une dimension dramatique et émotionnelle importante. 